\title{
BMJ Global Health Epidemic preparedness: Prenatal Zika virus screening during the next epidemic
}

\author{
Luxi Qiao, ${ }^{1,2}$ Celina M Turchi Martelli, ${ }^{3}$ Amber I Raja, ${ }^{1}$ Nuria Sanchez Clemente, ${ }^{1}$ \\ Thalia Velho Barreto de Araùjo, ${ }^{4}$ Ricardo Arraes de Alencar Ximenes, ${ }^{5,6}$ \\ Demócrito de Barros Miranda-Filho, ${ }^{6}$ Anna Ramond, ${ }^{1}$ Elizabeth B Brickley (1) ${ }^{1}$
}

To cite: Qiao L, Martelli CMT, Raja Al, et al. Epidemic preparedness: Prenatal Zika virus screening during the next epidemic. BMJ Global Health 2021;6:e005332. doi:10.1136/ bmjgh-2021-005332

Handling editor Senjuti Saha

Received 9 February 2021 Accepted 10 May 2021

Check for updates

(c) Author(s) (or their employer(s)) 2021. Re-use permitted under CC BY. Published by BMJ.

${ }^{1}$ Health Equity Action Lab, Department of Infectious Disease Epidemiology, London School of Hygiene \& Tropical Medicine, London, UK

${ }^{2}$ School of Medicine, Washington University in St Louis, St Louis, Missouri, USA

${ }^{3}$ Instituto Aggeu Magalhães, Fundação 0swaldo Cruz, Recife, Pernambuco, Brasil ${ }^{4}$ Departamento de Medicina Social, Universidade Federal de Pernambuco, Recife, Pernambuco, Brasil ${ }^{5}$ Departamento de Medicina Tropical, Universidade Federal de Pernambuco, Recife, Pernambuco, Brasil ${ }^{6}$ Departamento de Medicina Interna, Universidade de Pernambuco, Recife, Pernambuco, Brasil

Correspondence to Dr Elizabeth B Brickley; elizabeth.brickley@Ishtm.ac.uk

\section{ABSTRACT}

Zika virus (ZIKV) is a vectorborne infectious agent of global public health significance due to its potential to cause severe teratogenic outcomes. The question of whether health systems should consider adopting screening programmes for ZIKV infections during pregnancy warrants consideration. In this analysis, we apply the Wilson-Jungner framework to appraise the potential utility of a prenatal ZIKV screening programme, outline potential screening strategies within the case-finding pathway, and consider other epidemiological factors that may influence the planning of such a screening programme. Our evaluation of a potential prenatal ZIKV screening programme highlights factors affirming its usefulness, including the importance of Congenital Zika Syndrome as a public health problem and the existence of analogous congenital prenatal screening programmes for STORCH agents (syphilis, toxoplasmosis, others (eg human immunodeficiency virus, varicella-zoster virus, parvovirus B19), rubella, cytomegalovirus, and herpes simplex virus). However, our assessment also reveals key barriers to implementation, such as the need for more accurate diagnostic tests, effective antiviral treatments, increased social service capacity, and surveillance. Given that the reemergence of ZIKV is likely, we provide a guiding framework for policymakers and public health leaders that can be further elaborated and adapted to different contexts in order to reduce the burden of adverse ZIKV-related birth outcomes during future outbreaks.

\section{INTRODUCTION}

Screening programmes are a core public health service and can be a valuable tool in improving a population's health outcomes. ${ }^{1}$ The purpose of screening is to identify individuals in a 'healthy' population who are at higher risk of a specific health condition, in order to provide early treatment and/or intervention to high-risk individuals and thereby reduce the incidence of and/or mortality due to the condition in the full population. ${ }^{1}$ Prenatal screening programmes for congenital conditions, including those caused by
Summary box

- While it is well established that Zika virus (ZIKV) infections during pregnancy can have deleterious impacts on the health and well-being of congenitally infected offspring and their families, the question of whether prenatal screening for ZIKV may be warranted during epidemics remains open.

- Our analysis of a potential prenatal ZIKV screening programme using the Wilson-Jungner framework highlights factors affirming the utility of screening, such as the importance of Congenital Zika Syndrome as a public health problem, a growing understanding of the natural history of the disease, and the likely acceptability of a programme.

- However, our assessment also reveals key barriers to implementation, especially related to diagnostics, antiviral treatments, social service capacity, and surveillance.

- Adopting prenatal screening for ZIKV during an epidemic would enable pregnant persons to make more informed decisions about their pregnancy and facilitate the early identification of exposed newborns for specialised follow-up care, which may be of particular importance for children who present asymptomatically at birth but develop ZIKV-related sequelae in later childhood.

- Nevertheless, to be most impactful, prenatal screening programmes require cheaper and more precise ZIKV screening tests, as well as continued investment in the development of efficacious and safe therapeutics.

infectious diseases like Zika virus (ZIKV), aim for the early detection of risk factors for fetal anomalies in order to enable expectant parents to make informed choices about their pregnancy and aftercare. ${ }^{1}$

Similar to other STORCH (syphilis, toxoplasmosis, others [eg, HIV, varicella-zoster virus, parvovirus $\mathrm{B} 19]$, rubella, cytomegalovirus and herpes simplex virus) agents, ZIKV can be vertically transmitted across the placenta during pregnancy with potentially 
deleterious consequences for fetal development. Unlike other STORCH agents, ZIKV is vectorborne, and its transmission by competent Aedes spp. mosquitoes ${ }^{2}$ can facilitate explosive outbreaks with spatial and temporal clustering of neonates born with Congenital Zika Syndrome (CZS).$^{3-5}$ As of July 2019, a total of 87 countries and territories across Africa, the Americas, SouthEast Asia and the Western Pacific reported evidence of autochthonous mosquitoborne transmission of ZIKV, while an additional 61 countries and territories have demonstrated evidence of established Aedes spp. vectors without yet having documented ZIKV transmission. ${ }^{6}$

Given the severity of outcomes associated with congenital ZIKV infection and the threat of ZIKV reemergence in areas with prior outbreaks or emergence in new settings, ${ }^{7}$ the adoption of a screening programme for ZIKV infections during pregnancy warrants consideration. Here, we draw on the Wilson and Jungner evaluative framework $^{8}$ to analyse the feasibility and appropriateness of a prenatal screening programme during a ZIKV epidemic (summarised in table 1).

\section{CONSIDERATIONS FOR ASSESSING A PRENATAL SCREENING PROGRAMME FOR ZIKV INFECTION}

\section{The condition sought should be an important health problem}

Whereas maternal ZIKV infections are generally mild and self-limiting, a subset of congenital ZIKV infections may disrupt fetal development and result in structural malformations and functional neurodevelopmental impairments, which are collectively recognised as CZS. ${ }^{9-11}$ Although there is a wide spectrum of CZS severity, children with more severe cases of CZS are likely to have long-term needs for caregiving, medication and specialised support, which can incur substantial social and economic costs for affected individuals, their families and wider society. ${ }^{12}$ Additionally, evidence from a nationwide retrospective study linking routinely collected data in Brazil from 2015 to 2017 reported a case fatality rate of $9.4 \%$ (95\% CI: $8.4 \%$ to $10.6 \%$ ) among children with confirmed CZS diagnoses, with more than $90 \%$ of deaths occurring in infancy. ${ }^{13}$

\section{There should be a suitable test or examination}

ZIKV infections during pregnancy are primarily identified using nucleic acid amplification and serological tests. Nucleic acid amplification tests detect the presence of ZIKV RNA (ie, indicating acute infection) by reverse transcription-polymerase chain reaction (RT-PCR) in maternal whole blood, serum, plasma, urine and amniotic fluid in patients presenting, in general, $<7$ days from onset of symptoms, and serological tests detect binding and neutralising antibodies (ie, indicating acute or prior infection) against specific ZIKV antigens (eg, NS1) in whole blood, serum and plasma in patients presenting $\geq 7$ days from symptom onset. ${ }^{14}$ Ideally, a combination of the high specificity of molecular testing and the high sensitivity of serological testing for ZIKV would potentially allow for the most accurate identification of infections. ${ }^{15}$ While individual assay performances are highly variable and can depend on the type and timing of sample collected and, in the case of serological assays, the immunological cross-reactivity with other flaviviruses (eg, dengue virus (DENV)), the overall performances of ZIKV-specific assays are largely similar to the performances of routine diagnostic tests for other STORCH agents during pregnancy. ${ }^{16}$ Integrating ZIKV into the STORCH screening paradigm has the potential to improve standardisation and the differential diagnosis of other congenital infections.

\section{The natural history of the condition, including development from latent to declared disease, should be adequately understood}

The generally mild clinical presentation and the co-circulation of other immunologically cross-reactive flaviviruses in ZIKV-endemic areas has made establishing a case definition for ZIKV infection in pregnant persons challenging. ${ }^{15}$ A series of population-based prospective cohort studies (table 2) provide evidence that among pregnant individuals with laboratory-confirmed ZIKV, the risk of congenital ZIKV infection ranged between 5\% and $35 \%$, and the risk of adverse pregnancy and birth outcomes ranged between $2 \%$ and $46 \%,{ }^{17-25} 66$ with the high variability in adverse risk estimates due, in part, to the differing lengths of follow-up and outcome definitions used between studies. Children with CZS who survive infancy are expected to have a prognosis comparable with that of others who have conditions associated with microcephaly, epilepsy, and intellectual disability. ${ }^{26}$

\section{There should be a recognisable latent or early symptomatic stage}

While highly sensitive and specific laboratory diagnostic assays will improve the identification of maternal ZIKV infection before the onset of severe fetal anomalies, there is currently no available antiviral for impeding vertical transmission of ZIKV in humans ${ }^{27}$ or methods to accurately identify those fetuses who may be ZIKV-exposed but uninfected. Another complicating factor in recognising pregnancies at risk is the large fraction of asymptomatic ZIKV infections, ${ }^{28}$ which are reported to have a similar likelihood of adverse birth outcomes as symptomatic infections. ${ }^{29}$

\section{The test should be acceptable to the population}

While further research on attitudes of expectant families in relation to ZIKV screening is needed, non-invasive prenatal screening tests for congenital infections are generally well accepted. ${ }^{30} 31$ A study in Malaysia found that $81.8 \%$ of pregnant individuals who attended antenatal care were willing to be tested for ZIKV, with the lowest percentage found in those in the third trimester. ${ }^{32}$ Effective antenatal education on the various benefits 
Table 1 Summary of points supporting and not supporting each criterion of the Wilson and Jungner screening framework, with additional recommendations for futher research and/or public health actions

\begin{tabular}{|c|c|c|c|}
\hline Criteria & $\begin{array}{l}\text { Points supporting the } \\
\text { criterion }\end{array}$ & $\begin{array}{l}\text { Points not supporting the } \\
\text { criterion }\end{array}$ & $\begin{array}{l}\text { Recommendations for further } \\
\text { public health action(s) and/or } \\
\text { research }\end{array}$ \\
\hline $\begin{array}{l}\text { 1. The condition sought } \\
\text { should be an important health } \\
\text { problem }\end{array}$ & $\begin{array}{l}\text { ZIKV infection during } \\
\text { pregnancy may lead to } \\
\text { cases of CZS, which can } \\
\text { pose a significant burden } \\
\text { at the individual, family, } \\
\text { and societal level. }\end{array}$ & $\begin{array}{l}\text { ZIKV infection during } \\
\text { pregnancy occurs at a } \\
\text { lower frequency between } \\
\text { outbreaks in areas with } \\
\text { arbovirus circulation. }\end{array}$ & $\begin{array}{l}\text { Public health surveillance for } \\
\text { ZIKV epidemics to inform the } \\
\text { timing and type of prenatal } \\
\text { ZIKV screening programme. } \\
\text { Research on the long-term } \\
\text { health, social and economic } \\
\text { impacts of CZS on affected } \\
\text { children, families, and } \\
\text { communities. }\end{array}$ \\
\hline $\begin{array}{l}\text { 2. There should be a suitable } \\
\text { test or examination }\end{array}$ & $\begin{array}{l}\text { Validated and acceptable } \\
\text { molecular and serological } \\
\text { tests for detecting } \\
\text { ZIKV infections during } \\
\text { pregnancy are currently } \\
\text { available. }\end{array}$ & $\begin{array}{l}\text { Molecular tests have } \\
\text { narrow windows of } \\
\text { detection. } \\
\text { Serological tests are } \\
\text { subject to immunological } \\
\text { cross-reactivity with other } \\
\text { flaviviruses. }\end{array}$ & $\begin{array}{l}\text { Combining highly specific } \\
\text { molecular tests and highly } \\
\text { sensitive serological tests } \\
\text { to allow for more accurate } \\
\text { identification of ZIKV } \\
\text { infections. } \\
\text { Research to develop } \\
\text { diagnostic tests with enhanced } \\
\text { sensitivity and specificity. } \\
\text { Research to evaluate } \\
\text { performance of tests in } \\
\text { settings with endemic flavivirus } \\
\text { circulation. }\end{array}$ \\
\hline $\begin{array}{l}\text { 3. The natural history of } \\
\text { the condition, including } \\
\text { development from latent to } \\
\text { declared disease, should be } \\
\text { adequately understood }\end{array}$ & $\begin{array}{l}\text { Children with CZS who } \\
\text { survive infancy are } \\
\text { expected to have a } \\
\text { prognosis comparable } \\
\text { with children who } \\
\text { have other conditions } \\
\text { associated with } \\
\text { microcephaly, epilepsy, } \\
\text { and intellectual disability. }\end{array}$ & $\begin{array}{l}\text { Significant heterogeneity } \\
\text { remains in the risk } \\
\text { estimates of adverse } \\
\text { outcomes associated } \\
\text { with prenatal ZIKV } \\
\text { exposure, in part due } \\
\text { to inconsistencies in } \\
\text { the range of outcomes } \\
\text { assessed. } \\
\text { The prognosis of } \\
\text { children with prenatal } \\
\text { ZIKV exposure remains } \\
\text { uncertain beyond } 5 \text { years } \\
\text { of age. }\end{array}$ & $\begin{array}{l}\text { Expansion of infrastructure } \\
\text { and governance policies } \\
\text { for sustained data sharing } \\
\text { between Zika cohort studies. } \\
\text { Research using individual } \\
\text { participant data meta-analyses } \\
\text { of pregancy and paediatric } \\
\text { cohorts and standardised } \\
\text { outcomes to improve the } \\
\text { precision of risk estimates. } \\
\text { Research using paediatric } \\
\text { cohort studies and linked } \\
\text { electronic health records } \\
\text { to follow up children with } \\
\text { prenatal ZIKV exposure born } \\
\text { with or without apparent } \\
\text { manifestations of CZS. }\end{array}$ \\
\hline $\begin{array}{l}\text { 4. There should be a } \\
\text { recognisable latent or early } \\
\text { symptomatic stage }\end{array}$ & $\begin{array}{l}\text { Sensitive and specific } \\
\text { laboratory diagnostic } \\
\text { assays have the potential } \\
\text { to detect maternal ZIKV } \\
\text { infections before the } \\
\text { onset of severe fetal } \\
\text { anomalies. }\end{array}$ & $\begin{array}{l}\text { Antivirals for impeding } \\
\text { vertical transmission of } \\
\text { ZIKV are not currently } \\
\text { available. } \\
\text { Prenatal and postnatal } \\
\text { testing to identify } \\
\text { offspring who may } \\
\text { be ZIKV-exposed but } \\
\text { uninfected remains } \\
\text { limited. } \\
\text { A large portion of } \\
\text { ZIKV infections are } \\
\text { asymptomatic. }\end{array}$ & $\begin{array}{l}\text { Public health efforts to improve } \\
\text { antenatal care attendance. } \\
\text { Monitoring of children with } \\
\text { prenatal ZIKV exposure who } \\
\text { present asymptomatically at } \\
\text { birth for developmental delays } \\
\text { and late-onset sequelae of } \\
\text { congenital infections. } \\
\text { Research to develop antiviral } \\
\text { treatments to block vertical } \\
\text { transmission. } \\
\text { Research to improve the safety } \\
\text { and effectiveness of testing for } \\
\text { offspring infection status (eg, } \\
\text { via amniocentesis or neonatal } \\
\text { serum/urine testing). }\end{array}$ \\
\hline
\end{tabular}


Table 1 Continued

\section{Criteria}

5. The test should be acceptable to the population

Points supporting the criterion

- Non-invasive prenatal screening tests for STORCH agents are generally well accepted.
Points not supporting the criterion

- There is limited research on the attitudes towards prenatal screening tests for ZIKV.
Recommendations for further public health action(s) and/or research

- Public health education and communication on risks of prenatal ZIKV infections and screening methods.

- Research on attitudes of expectant families in ZIKVendemic settings.

6. There should be an agreed $\quad$ Both the pregnant person - Local policies may differ policy on whom to treat as patients

- Prenatal counselling following positive screening test result.

- Postnatal clinical and social and offspring would be considered as patients due to the potential for vertical transmission of ZIKV infection during pregnancy. with regards to the rights of pregnant persons and their offspring (eg, with respect to pregnancy terminations). support for children with prenatal exposure to ZIKV and their families.

- Research to evaluate indirect effects of CZS on caregivers' mental health, social support, and lived experiences.

\begin{abstract}
7. There should be an accepted treatment for patients with recognised disease
\end{abstract}

8. Facilities for diagnosis and treatment should be available
Anticipatory guidance to caregivers and early referrals to appropriate specialists and early intervention programmes for the affected child and family is well accepted.
There are no available vaccines or antiviral treatments.

- Access to unrestricted legal abortion remains rare in many settings where ZIKV is endemic.

- Expanded access to specialised treatment programmes for children with CZS.

- Research to develop vaccines to prevent ZIKV infection during pregnancy.

- Research to develop antiviral treatments to prevent vertical transmission.

- Diagnostics and expertise developed during the last ZIKV epidemic exist.
- Utilisation of existing ZIKV diagnostic assays require significant resources.

- Follow-up care for CZS patients and their families requires long-term financial commitment from health systems.

9. The cost of case finding
should be economically
balanced in relation to possible
expenditure on medical care
as a whole

Screening is likely to be most cost-effective during an outbreak situation.
In non-outbreak situations, screening may not be cost-effective, as screening costs could be more than the preventable costs.
Public health efforts to improve accessibility and affordability of tests.

- Research to develop rapid, low-cost, point-of-care testing.

- Research into effectiveness of interventions in clinically relevant subgroups to inform targeted treatment.

- Enhancing capacity to rapidly integrate ZIKV screening into existing prenatal testing platforms during outbreak situations.

- Research to develop multiplex prenatal screening assays, including ZIKV testing. 


\begin{tabular}{|c|c|c|c|}
\hline Criteria & $\begin{array}{l}\text { Points supporting the } \\
\text { criterion }\end{array}$ & $\begin{array}{l}\text { Points not supporting the } \\
\text { criterion }\end{array}$ & $\begin{array}{l}\text { Recommendations for further } \\
\text { public health action(s) and/or } \\
\text { research }\end{array}$ \\
\hline $\begin{array}{l}\text { 10. Case finding should be a } \\
\text { continuing process and not as } \\
\text { a once-and-for-all project }\end{array}$ & $\begin{array}{l}\text { Ultrasound may be } \\
\text { used with or in lieu of } \\
\text { laboratory testing to } \\
\text { detect cases of CZS. } \\
\text { Routine paediatric } \\
\text { evaluations and } \\
\text { developmental screening } \\
\text { may be used to detect } \\
\text { CZS-related anomalies at } \\
\text { a later stage. }\end{array}$ & $\begin{array}{l}\text { Maternal ZIKV infections } \\
\text { may be asymptomatic, } \\
\text { and ZIKV-exposed infants } \\
\text { may present without } \\
\text { typical CZS features. }\end{array}$ & $\begin{array}{l}\text { Increased monitoring of } \\
\text { pregnancies during an } \\
\text { outbreak situation. } \\
\text { Continued monitoring } \\
\text { of symptomatic and } \\
\text { asymptomatic children with } \\
\text { prenatal ZIKV exposure } \\
\text { for developmental delays } \\
\text { and late-onset sequelae of } \\
\text { congenital infections. } \\
\text { Research evaluating paired } \\
\text { mother-offspring testing to } \\
\text { detect congenital infections } \\
\text { postnatally. }\end{array}$ \\
\hline
\end{tabular}

CZS, Congenital Zika Syndrome; STORCH, (syphilis, toxoplasmosis, others (eg, human immunodeficiency virus, varicella-zoster virus, parvovirus B19), rubella, cytomegalovirus, and herpes simplex virus); ZIKV, Zika virus.

and risks of a ZIKV screening programme may further increase public acceptance.

\section{There should be an agreed policy on whom to treat as patients}

Due to the potential for vertical transmission of ZIKV infection during pregnancy, both the pregnant person and offspring would be considered as patients. While evaluations, clinical decision making and treatment after birth are mainly focused on the offspring, it is crucial to recognise the unique vulnerabilities of parents of CZS patients, such as the increased risk of developing anxiety and depression. ${ }^{33}$

\section{There should be an accepted treatment for patients with recognised disease}

At present, there are no available vaccines to prevent maternal infections or approved antiviral treatments to limit ZIKV infection or block vertical transmission and acute clinical care for ZIKV infection in pregnancy is mainly focused on treating maternal symptoms with analgesics and antipyretics. ${ }^{34}$ In the absence of specific antiviral treatments, the screening programme would aim to counsel expectant parents on CZS-related risks and clinical decisions including, in certain settings, the option of elective termination of the pregnancy, as is the case for cytomegalovirus, ${ }^{35} 36$ and to identify prenatally ZIKV-exposed children for further monitoring and/or treatment for CZS.

Of note, access to unrestricted legal abortion remains rare in Latin America, with the majority of countries having complete prohibition or restrictive laws. Thus, termination is not an option for many pregnant individuals with ZIKV infection, even if microcephaly and/or brain abnormality are detected at ultrasound examination or ZIKV is detected early in the pregnancy. However, there are other interventions that can be offered to pregnant persons and their families, such as supportive measures to mitigate the emotional impact of the potential adverse outcomes. ${ }^{37}$

For newborns with CZS, anticipatory guidance to caregivers and early referrals to appropriate specialists and support groups is crucial. Although confirmatory research is ongoing, early intervention programmes addressing CZS are well accepted and expected to result in an overall improved functional performance. ${ }^{38}$

\section{Facilities for diagnosis and treatment should be available}

In the absence of authorised point-of-care rapid tests, ${ }^{39}$ ZIKV diagnostics rely on expensive, high-complexity and time-intensive diagnostic RT-PCR and serological assays requiring skilled technicians, laboratory facilities and specialised equipment. Further, adequate follow-up care for ZIKV-exposed pregnancies and tertiary care for children with severe manifestations of CZS (eg, severe microcephaly) requires significant on-going financial commitment from public health systems.

\section{The cost of case finding should be economically balanced in relation to possible expenditure on medical care as a whole The cost of a prenatal infection screening programme depends on the annual number of pregnancies, whereas the preventable costs depend on the maternal infection rate. Thus, if the screening costs are less than the prevent- able costs, then a screening programme will be cost- effective and should be adopted. ${ }^{40}$ This is likely to be the case during a ZIKV outbreak, when local maternal infec- tion rates would be increased and the positive predictive value (PPV) of testing would be at its optimal.}

\section{Case finding should be a continuing process and not as a once-and-for-all project}

Continuing examinations allow a programme to become more efficient and economical, and regular offers of 


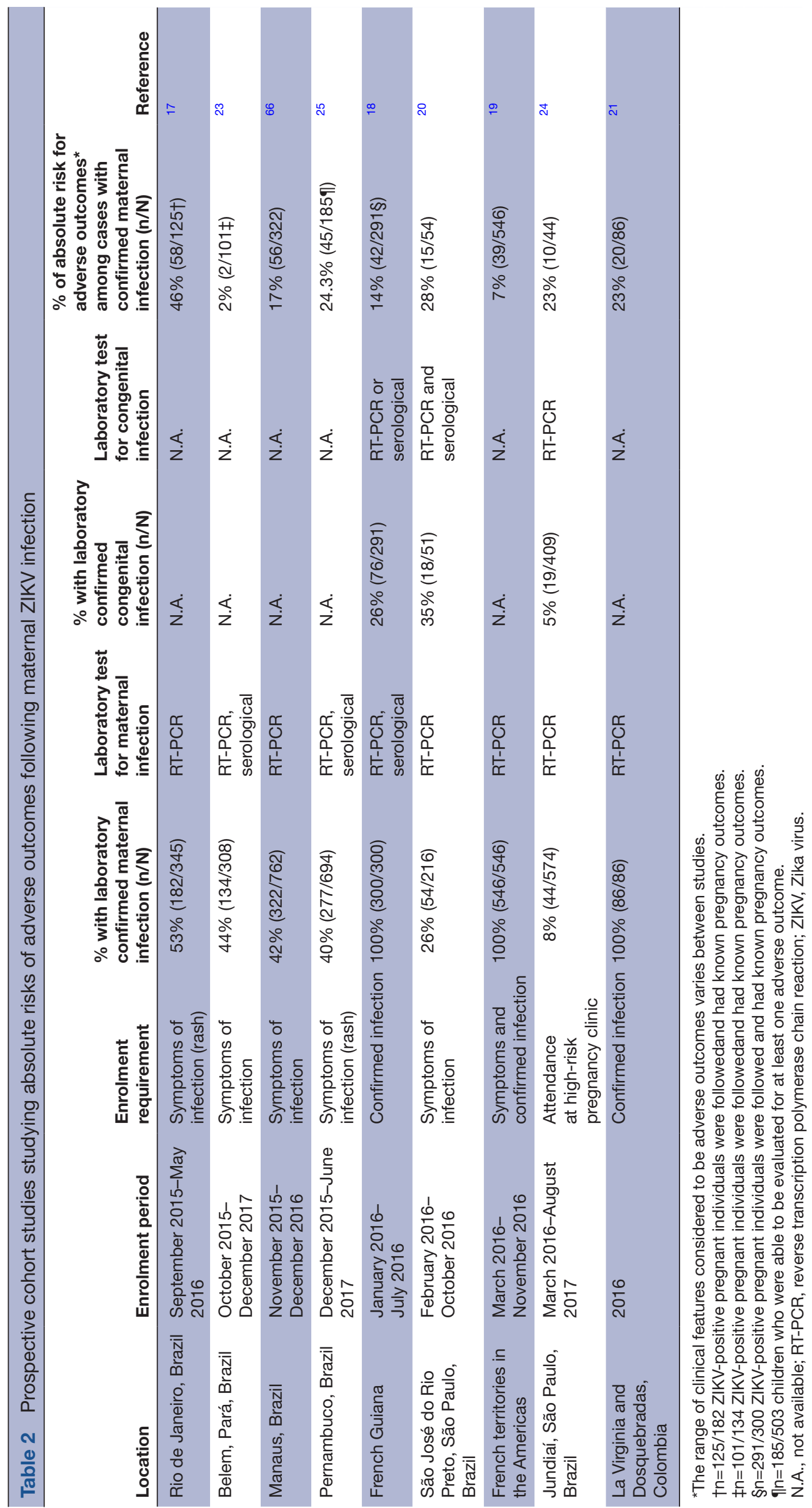


examination are likely to gradually cover more and more of the population at risk. In addition to or in lieu of laboratory testing, continued monitoring and case finding of at-risk pregnant individuals can be done using ultrasound. Although microcephaly was initially described as the hallmark feature of in utero exposure to ZIKV infection and presentation of CZS at birth, ${ }^{41}$ it is now well accepted that newborns can have CZS in the absence of microcephaly. ${ }^{42}{ }^{43}$ Notably, head circumference (HC) may be increased in some cases due to severe ventriculomegaly. ${ }^{44}$

Given reports of late-onset ZIKV-associated anomalies among children with a normal HC at birth, ${ }^{45}$ it is recommended that healthcare providers remain vigilant for possible sequelae of congenital infection ${ }^{46}$ even in the absence of typical phenotypic features of CZS. ${ }^{47}$ The US Centers for Disease Control and Prevention recommends laboratory testing of infants with clinical features of CZS regardless of maternal laboratory results, as well as ZIKV-exposed infants without CZS features. ${ }^{46}$ While the specific clinical evaluation and management of CZS depends on the ZIKV status of the infant and/or mother, it is recommended that a cranial ultrasound, as well as audiology and ophthalmology assessments are performed by 1 month of age ${ }^{46}$ Follow-up for 6 months to 1 year is also advised to assess for the development of any later onset clinical manifestations that could be associated with CZS (eg, epilepsy, developmental delays or delay in head growth ${ }^{46}$ and to facilitate prompt referral to appropriate specialists, and early intervention programmes if required. ${ }^{46}$

\section{PRENATAL ZIKV SCREENING IN PRACTICE: BENEFIT VERSUS HARM}

A major challenge in implementing a screening programmes is balancing the benefits with the harms of screening. ${ }^{1}$ The benefit of prenatal screening for ZIKV during an epidemic would be implementation of early interventions that can better support families by providing parents with information to help make informed choices, as well as providing newborns with specialist care. There are also societal benefits of an antenatal screening programme such as the potential costs saved by preventing long-term disabilities. A screening programme could also drive positive changes in a health system that provides better overall support for families who care for children with congenital disabilities, as well as potentially driving research for improved diagnostic testing and antiviral treatments. Additional benefits of prenatal screening for congenital infections include an opportunity to educate seronegative individuals about behaviours that increase risk of transmission. ${ }^{48}$ For example, a study in France showed improved hygiene education for expectant mothers and their partners reduced cytomegalovirus infection rates during the pregnancy. ${ }^{49}$
As there will always be false positives and false negatives, a screening programme may introduce unintended harms. ${ }^{1}$ Whereas false-negative tests (ie, low sensitivity) will lead to missed opportunities for further evaluation and delayed detection of CZS, ${ }^{50}$ false-positive tests (ie, low specificity) have the potential to lead to adverse outcomes including potentially unwarranted pregnancy terminations. A screening test's PPV and negative predictive value (NPV) (ie, the probability that subjects with a positive or negative screening result truly do or do not have the condition, respectively) depend not only on the sensitivity and specificity of the screening test but also on the prevalence of the condition in the population. In a population with low ZIKV circulation, screening would result in a high proportion of false positives requiring further invasive confirmatory testing, which brings additional risks to the fetus and mother, as well as the potential psychosocial repercussions that need to be considered. ${ }^{51}$ In addition to the impact on the individual/family, the economic costs of screening to a country's health system is also important, especially if the majority of individuals being screened do not have the condition.

Another factor that complicates the benefit-harm analysis is the current uncertainty in the estimated risk of adverse outcomes following detection of a ZIKV infection during pregnancy, which may challenge the clinical decision-making process and be a source of significant anxiety to expectant parents. Given that only limited quantities of new data are likely to become accessible before the next reemergence of ZIKV, large-scale individual participant data meta-analyses of existing cohort studies, such as those proposed by the Zika Brazilian Cohorts Consortium ${ }^{52}$ the European Commission Zika Consortia Vertical Transmission Study Group ${ }^{53}$ and the Zika Virus Individual Participant Data Consortiun, ${ }^{37} 54$ will be essential for standardising exposure and outcome definitions and improving understanding of the full spectrum of CZS outcomes including rare outcomes, the precision of risk estimates, and the sources of heterogeneity in the risk estimates. In addition, efforts to link the longitudinal electronic health records (eg, hospitalisations and deaths) of children in ZIKV-affected regions, such as through the Centro de Integração de Dados e Conhecimentos para Saúde Birth Cohort in Brazil, ${ }^{55}$ will yield valuable insights regarding the long-term prognosis of children with CZS.

Ultimately, the decision to implement a prenatal ZIKV screening programme is highly dependent on the context of a country's health system, resources available and guiding ethical principles. Screening criteria that incorporate the values and priorities of a country and its population may help balance the benefits and harms of a screening programme. Anticipated benefits and harms can be tested using pilot projects, which will also generate important data about cost-effectiveness and efficiency. Additional research that more precisely defines risk estimates of adverse fetal outcomes or leads to the 
development of lower cost and/or more accurate diagnostics or of novel therapeutics will also likely tip the scale.

\section{POTENTIAL STRATEGIES FOR PRENATAL ZIKV SCREENING DURING AN OUTBREAK}

To help illustrate population-based prenatal screening for ZIKV, here, we present a general flow-diagram with recommended components that can be further elaborated to fit each settings' needs and available resources. In settings with a history of recent ZIKV circulation and a high seroprevalence, a universal screening strategy based on serological testing at the first antenatal visit could be adopted to identify seronaive individuals who may be at heightened risk of ZIKV infections and would benefit from repeated testing during pregnancy (figure 1; option 1). The chief limitations of this approach are cross-reactivity with DENV and other flaviviruses ${ }^{56}$ as well as false reassurance and reduced preventive behaviours and prenatal monitoring. ${ }^{15}$ An alternative approach for universal screening would be to test all pregnant individuals near the end of the first trimester using a combination of serological and molecular assays to detect recent and acute infections (option 2). While testing could be repeated during the second or third trimester, current evidence suggests maternal infection during the first trimester is associated with the highest risk of CZS and vertical transmission, ${ }^{19} 3957$ and the option of elective
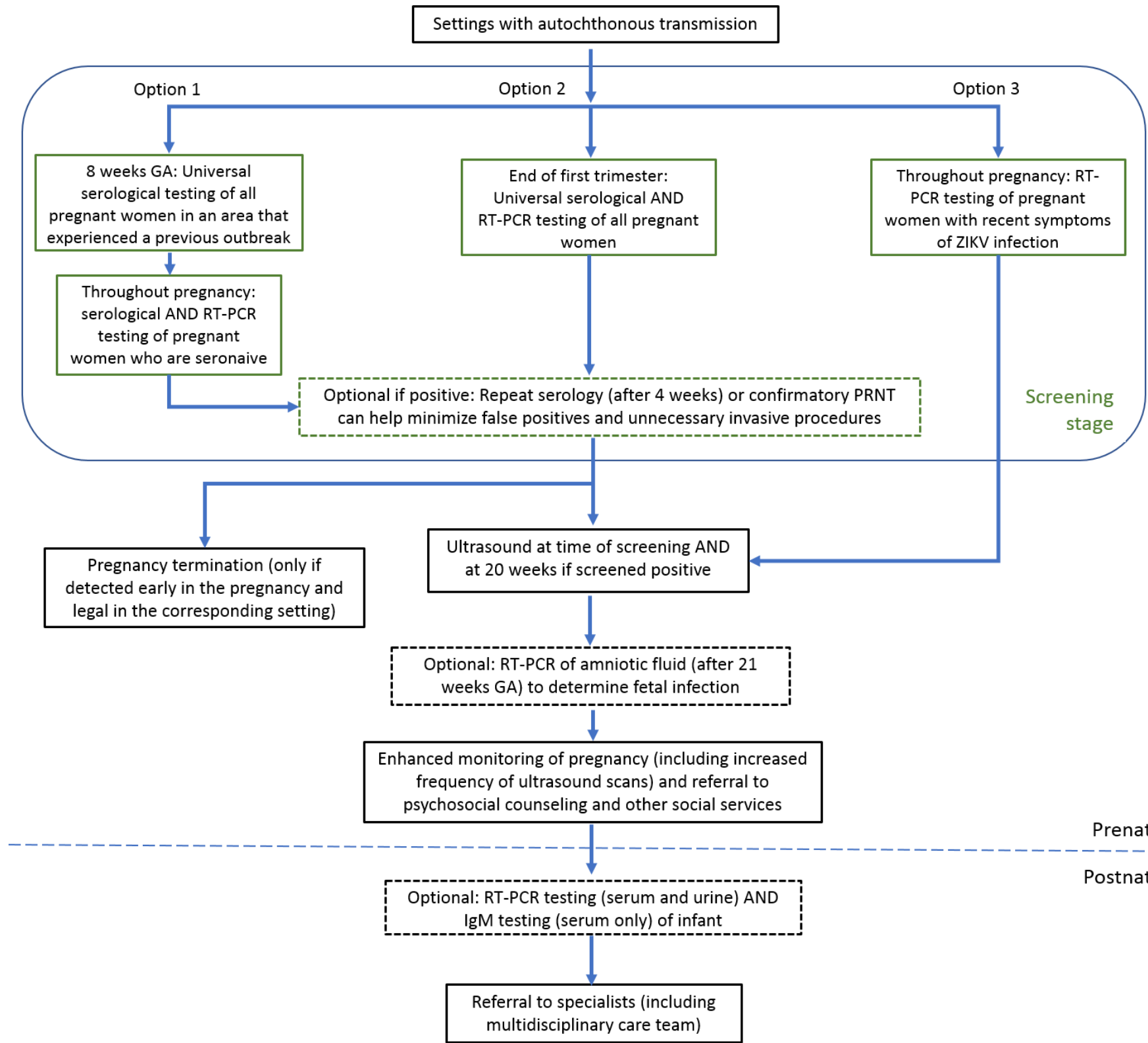

Prenatal

Postnatal

Figure 1 Potential ZIKV screening strategies during pregnancy. This flow chart illustrates the progression for different CZS screening strategies during pregnancy with options for increased confirmatory testing depending on resources available. ${ }^{65}$ CZS, Congenital Zika Syndrome; GA, gestational age; IgM, immunoglobulin M; PRNT, plaque reduction neutralisation test; RT$\mathrm{PCR}$, reverse transcription-polymerase chain reaction; ZIKV, Zika virus. 
pregnancy termination remains available in some, but not all, countries. Lastly, ZIKV screening via molecular testing could be targeted to pregnant individuals who present with symptoms consistent with acute ZIKV infection (option 3). Although targeting only symptomatic individuals can help reduce operating costs, more than $60 \%$ of ZIKV infections that are asymptomatic may be missed. ${ }^{28}$ A potential strategy that can be added to option 3 to reduce cost and to cover asymptomatic infections, is to pool asymptomatic samples before RT-PCR with workup of individual samples only if pooled test results are positive. This has been used with sufficient diagnostic accuracy for SARS-CoV-2 with pool sizes up to 30 samples. ${ }^{58}$

Modification to the diagram may be warranted in settings with mostly travel-related infections. ZIKV seroprevalence varies hugely among traveller populations compared with resident populations living in areas with active transmission $(<2 \%$ in travellers vs up to $60 \%$ in the local population, ${ }^{16}$ due to differing risks of exposure as well as access to and affordability of preventive measures. ${ }^{59}$ For settings with mostly travel-related transmission, a routine questionnaire, which is recommended by the American College of Obstetricians and Gynecologists to identify possible exposure before considering the need for testing, ${ }^{60}$ can be applied first to identify those at risk before initiating any of the options presented.

Following a positive screening result, an ultrasound should be obtained as evidence suggests a normal HC to femur length ratio in fetuses without microcephaly is associated with an $87 \%$ NPV for the postnatal detection of congenital ZIKV-associated injuries. ${ }^{61}$ Further laboratory testing to determine offspring infection status can be performed either before (via amniocentesis, which may introduce additional risks to the pregnancy and for which data regarding PPV and NPV are unknown ${ }^{62}$ ) or as soon as possible after birth (using serum and/ or urine) ${ }^{2462}$ In addition to standard evaluations, all infants with known prenatal exposure to ZIKV infection should also receive a head ultrasound, an opthalmological examination, and a hearing examination. Lastly, infants with laboratory or clinical evidence of CZS should have referrals to early intervention service programmes and family support services in addition to clinical consultations regarding child development, infectious disease, neurology, and other specialities as indicated based on clinical findings. ${ }^{62}$

\section{TIMING FOR IMPLEMENTING A PRENATAL ZIKV SCREENING PROGRAMME}

A crucial prerequisite to the effective implementation of a screening programme is surveillance. By systematically monitoring the incidence of infections and associated disease, such as congenital anomalies, surveillance helps to inform the timing and type of screening programme adopted by providing information on the rate of community-wide transmission. In addition, long-term surveillance may also yield information on the likely proportion of the pregnant population with preexisting protective immunity to ZIKV. Although there is limited evidence on the duration of neutralising antibodies following a ZIKV infection, ${ }^{63}$ it is plausible that, in populations with a high seroprevalence following an outbreak (eg, $63 \%$ in Salvador, Brazil) ${ }^{64}$ there may be a lower maternal infection rate in future epidemics. Thus, given the synergistic utility of screening and surveillance, resuming or establishing the latter may be a necessary preamble to effective implementation of a screening programme.

\section{CONCLUSION}

Designing a screening programme for ZIKV during pregnancy is a complex process that requires careful consideration. Maternal infection is often asymptomatic or consists of only mild, non-specific symptoms and vertical transmission rates are variable but have potentially lifealtering consequences. Normally, screening provides medical benefits from early treatment. However, while early intervention allows for anticipatory support of newborns and families affected by CZS, there are no treatments currently available to prevent the vertical transmission of ZIKV or to minimise the risk of potential congenital anomalies, and termination of pregnancy is not always a legal option. This initial assessment of the feasibility and utility of a prenatal ZIKV screening programme using the Wilson and Jungner criteria highlights affirmative factors such as acceptability and potential positive impact of such a programme, even in the absence of curative treatment and accurate diagnostics. In addition, consideration of the timing, as well as the overall benefits and harms of implementing a prenatal ZIKV screening programme are necessary foundations for more context-dependent decision making. Moving forward, research should be directed into the natural history of CZS, especially the long-term prognosis of ZIKV-exposed children who present with defects before or at birth and those who present asymptomatically at birth but develop clinical manifestations later on. The development of screening tests with enhanced precision and decreased costs and the introduction of efficacious, safe treatment will further improve the benefit-to-risk balance.

Twitter Elizabeth B Brickley @ebbrickley

Contributors All authors contributed the work, including the drafting and/or revision of the manuscript, and provided final approval for the submitted version.

Funding This study was supported by the Washington University School of Medicine Summer Research Program, the British Council Newton Fund (57418645), the Wellcome Trust \& the UK's Department for International Development (205377/Z/16/Z), the European Union's Horizon 2020 research and innovation program under ZikaPLAN grant agreement No. 734584, the Conselho Nacional de Desenvolvimento Científico e Tecnológico (309722/2017-9; 308590/2013-9; and 306708/2014-0), Secretaria de Vigilância em Saúde/ Ministério da Saúde de Brasil Resposta à Emergência em Saúde Pública - Zika vírus e Microcefalia (837058/2016), the Conselho Nacional de Desenvolvimento Científico e Tecnológico, the Coordenação de Aperfeiçoamento de Pessoal de Nível Superior, \& the Departamento de Ciência e Tecnologia for Prevenção e Combate a 
o vírus Zika I (440839/2016-5). https://ec.europa.eu/programmes/horizon2020/, https://zikaplan.tghn.org/, http://www.capes.gov.br/, http://www.cnpq.br/, http:// rebrats.saude.gov.br/noticias/59DECIT.

Competing interests None declared.

Patient consent for publication Not required.

Provenance and peer review Not commissioned; externally peer reviewed.

Data availability statement All data are based on published articles and any relevant abstracted data are available in the article.

Open access This is an open access article distributed in accordance with the Creative Commons Attribution 4.0 Unported (CC BY 4.0) license, which permits others to copy, redistribute, remix, transform and build upon this work for any purpose, provided the original work is properly cited, a link to the licence is given, and indication of whether changes were made. See: https://creativecommons.org/ licenses/by/4.0/.

ORCID iD

Elizabeth B Brickley http://orcid.org/0000-0003-0280-2288

\section{REFERENCES}

1 World Health Organization. Screening programmes: a short guide. Denmark: Organization WH, 2020.

2 Gregory CJ, Oduyebo T, Brault AC. Modes of transmission of Zika virus. Journal of Infectious Diseases 2017;216:S875-83.

3 de Souza WV, de Albuquerque M, Vasquez E. Microcephaly epidemic related to the Zika virus and living conditions in Recife, northeast Brazil. BMC Public Health 2018;18.

4 Huang Y-JS, Higgs S, Vanlandingham DL. Arbovirus-mosquito vector-host interactions and the impact on transmission and disease pathogenesis of arboviruses. Front Microbiol 2019;10:22.

5 Zhang Q, Sun K, Chinazzi M, et al. Spread of Zika virus in the Americas. Proc Natl Acad Sci U S A 2017;114:E4334-43.

6 World Health Organization. Countries and territories with current or previous Zika virus transmission, 2019.

7 World Health Organization. Zika epidemiology update. World Health Organization, 2019

8 Wilson JMG, Jungner G. Principles and practice of screening for disease. Geneva, Switzerland: World Health Organization, 1968.

9 Melo ASdeO, Aguiar RS, Amorim MMR, et al. Congenital Zika virus infection: beyond neonatal microcephaly. JAMA Neurol 2016;73:1407-16.

10 Martines RB, Bhatnagar J, de Oliveira Ramos AM, et al. Pathology of congenital Zika syndrome in Brazil: a case series. Lancet 2016;388:898-904.

11 Miranda-Filho DdeB, Martelli CMT, Ximenes RAdeA, et al. Initial description of the presumed congenital Zika syndrome. Am J Public Health 2016;106:598-600.

12 Avci DK, Oner E. Examination of the knowledge, attitude and behaviours of pregnant women on screening tests made during pregnancy. East J Med 2018;23:84-9.

13 Costa MCN, Cardim LL, Teixeira MG, et al. Case fatality rate related to microcephaly congenital Zika syndrome and associated factors: a nationwide retrospective study in Brazil. Viruses2020;12.

14 World Health Organization. Interim guidance: laboratory testing for Zika virus infection, 2016.

15 Ximenes RAdeA, Miranda-Filho DdeB, Brickley EB, et al. Zika virus infection in pregnancy: Establishing a case definition for clinical research on pregnant women with rash in an active transmission setting. PLoS Negl Trop Dis 2019;13:e0007763.

16 Voordouw B, Rockx B, Jaenisch T, et al. Performance of Zika assays in the context of Toxoplasma gondii, parvovirus B19, rubella virus, and cytomegalovirus (torch) diagnostic assays. Clin Microbiol Rev 2019;33:e00130-18

17 Brasil P, Pereira JP, Moreira ME, et al. Zika virus infection in pregnant women in Rio de Janeiro. N Engl J Med 2016;375:2321-34.

18 Pomar L, Vouga M, Lambert V, et al. Maternal-Fetal transmission and adverse perinatal outcomes in pregnant women infected with Zika virus: prospective cohort study in French Guiana. BMJ 2018;363:k4431.

19 Hoen B, Schaub B, Funk AL, et al. Pregnancy outcomes after ZIKV infection in French territories in the Americas. N Engl J Med 2018;378:985-94.
20 Nogueira ML, Nery Júnior NRR, Estofolete CF, et al. Adverse birth outcomes associated with Zika virus exposure during pregnancy in São José do Rio Preto, Brazil. Clin Microbiol Infect 2018;24:646-52.

21 Rodriguez-Morales AJ, Cardona-Ospina JA, Ramirez-Jaramillo $V$, et al. Diagnosis and outcomes of pregnant women with Zika virus infection in two municipalities of Risaralda, Colombia: second report of the ZIKERNCOL study. Travel Med Infect Dis 2018;25:20-5.

22 N Costa MC, Cardim LL, Teixeira MG, et al. Case fatality rate related to microcephaly congenital Zika syndrome and associated factors: a nationwide retrospective study in Brazil $\dagger$. Viruses 2020;12. doi:10.3390/v12111228. [Epub ahead of print: 2910 2020].

23 de Oliveira CS, de Matos HJ, Ramos FLdeP, et al. Risk of Zika virus-associated birth defects in congenital confirmed cases in the Brazilian Amazon. Rev Panam Salud Publica 2020;44:e116.

24 Sanchez Clemente N, Brickley EB, Paixão ES, et al. Zika virus infection in pregnancy and adverse fetal outcomes in São Paulo state, Brazil: a prospective cohort study. Sci Rep 2020;10:12673.

25 Ximenes RAdeA, Miranda-Filho DdeB, Montarroyos UR, et al. Zikarelated adverse outcomes in a cohort of pregnant women with rash in Pernambuco, Brazil. PLoS Negl Trop Dis 2021;15:e0009216.

26 Wheeler AC. Development of infants with congenital Zika syndrome: what do we know and what can we expect? Pediatrics 2018;141:s154-60

27 Mesci P, Macia A, Moore SM, et al. Blocking Zika virus vertical transmission. Sci Rep 2018;8:1218.

28 Haby MM, Pinart M, Elias V, et al. Prevalence of asymptomatic Zika virus infection: a systematic review. Bull World Health Organ 2018;96:402-13.

29 Paixao ES, Leong W-Y, Rodrigues LC, et al. Asymptomatic prenatal Zika virus infection and congenital Zika syndrome. Open Forum Infect Dis 2018:5: ofy073.

30 Din ES, Brown CJ, Grosse SD, et al. Attitudes toward newborn screening for cytomegalovirus infection. Pediatrics 2011:128:e1434-42.

31 Diener ML, Shi K, Park AH. A cross-sectional study of caregiver perceptions of congenital cytomegalovirus infection: knowledge and attitudes about screening. J Pediatr 2020;218:151-6.

32 Wong LP, Alias H, Hassan J, et al. Attitudes towards Zika screening and vaccination acceptability among pregnant women in Malaysia. Vaccine 2017;35:5912-7.

33 Kuper H, Lopes Moreira ME, Barreto de Araújo TV, et al. The association of depression, anxiety, and stress with caring for a child with congenital Zika syndrome in Brazil; results of a cross-sectional study. PLoS Negl Trop Dis 2019;13:e0007768.

34 CDC. Zika Virus: Clinical evaluation \& disease, 2019. Available: https://www.cdc.gov/zika/hc-providers/preparing-for-zika/clinical evaluationdisease.html [Accessed June 19th 2019].

35 Lunardi S, Lorenzoni F, Ghirri P. Universal Screening for Congenital CMV Infection. In: Barria RM, ed. Update on critical issues on infant and neonatal care. IntechOpen, 2019.

36 Adler SP. Screening for cytomegalovirus during pregnancy. Infect Dis Obstet Gynecol 2011;2011:1-9.

37 Zika Virus Individual Participant Data Consortium. The Zika virus individual participant data Consortium: a global initiative to estimate the effects of exposure to Zika virus during pregnancy on adverse fetal, infant, and child health outcomes. Trop Med Infect Dis 2020;5:152.

38 Brandão MdeB, Frota LMdaCP, Miranda JL, et al. Family-Centered early intervention program for Brazilian infants with congenital Zika virus syndrome: a pilot study. Phys Occup Ther Pediatr 2019;39:642-54.

39 Brasil P, Vasconcelos Z, Kerin T, et al. Zika virus vertical transmission in children with confirmed antenatal exposure. Nat Commun 2020;11:3510.

40 Joss AW, Chatterton JM, Ho-Yen DO. Congenital toxoplasmosis: to screen or not to screen? Public Health 1990;104:9-20.

41 Schuler-Faccini L, Ribeiro EM, Feitosa IML, et al. Possible Association Between Zika Virus Infection and Microcephaly - Brazil, 2015. MMWR Morb Mortal Wkly Rep 2016;65:59-62.

42 Linden vander V, Pessoa A, Dobyns WB. Description of 13 infants born during October 2015-January 2016 with congenital Zika virus infection without microcephaly at birth. Morb Mortal Wkly Rep 2016:65:1343-8.

43 Sanz Cortes M, Rivera AM, Yepez M, et al. Clinical assessment and brain findings in a cohort of mothers, fetuses and infants infected with Zika virus. Am J Obstet Gyncecol 2018;218:e1-36.

44 Schaub B, Gueneret M, Jolivet E, et al. Ultrasound imaging for identification of cerebral damage in congenital Zika virus syndrome: a case series. Lancet Child Adolesc Health 2017:1:45-55. 
45 Adams Waldorf KM, Olson EM, Nelson BR, et al. The aftermath of Zika: need for long-term monitoring of exposed children. Trends Microbiol 2018;26:729-32.

46 Oduyebo T, Polen KN, Walke HT, et al. Update: interim guidance for health care providers caring for pregnant women with possible Zika virus exposure - United States (including U.S. territories), July 2017. Morb Mortal Wkly Rep 2017;66:781-93.

47 Heald-Sargent T, Muller W. Zika virus: a review for pediatricians. Pediatr Ann 2017;46:e428-32.

48 Demmler GJ. Screening for congenital cytomegalovirus infection: a tapestry of controversies. J Pediatr 2005;146:162-4.

49 Vauloup-Fellous C, Picone O, Cordier A-G, et al. Does hygiene counseling have an impact on the rate of CMV primary infection during pregnancy? results of a 3-year prospective study in a French Hospital. J Clin Virol 2009;46 Suppl 4:S49-53.

50 Matheus S, Talla C, Labeau B, et al. Performance of 2 commercial serologic tests for diagnosing Zika virus infection. Emerg Infect Dis 2019;25:1153-60.

51 Hancock WT, Soeters HM, Hills SL, et al. Establishing a Timeline to Discontinue Routine Testing of Asymptomatic Pregnant Women for Zika Virus Infection - American Samoa, 2016-2017. MMWR Morb Mortal Wkly Rep 2017;66:299-301.

52 Alecrim MdasGC, Amorim MMRde, Araújo TVBde, et al. Zika Brazilian cohorts (ZBC) Consortium: protocol for an individual participant data meta-analysis of congenital Zika syndrome after maternal exposure during pregnancy. Viruses 2021;13. doi:10.3390/ v13040687. [Epub ahead of print: 1604 2021].

53 Ades AE, Brickley EB, Alexander N, et al. Zika virus infection in pregnancy: a protocol for the joint analysis of the prospective cohor studies of the ZIKAlliance, ZikaPLAN and ZIKAction consortia. BMJ Open 2020;10:e035307.

54 Wilder-Smith A, Wei Y, Araújo TVBde, et al. Understanding the relation between Zika virus infection during pregnancy and adverse fetal, infant and child outcomes: a protocol for a systematic review and individual participant data meta-analysis of longitudinal studies of pregnant women and their infants and children. BMJ Open 2019;9:e026092.
55 Paixao ES, Cardim LL, Falcao IR, et al. Cohort profile: Centro de Integração de Dados E Conhecimentos para Saúde (CIDACS) birth cohort. Int J Epidemiol 2021;50:37-8.

56 Peters R, Stevenson M. Zika virus diagnosis: challenges and solutions. Clin Microbiol Infect 2019;25:142-6.

57 Shapiro-Mendoza CK, Rice ME, Galang RR, et al. Pregnancy Outcomes After Maternal Zika Virus Infection During Pregnancy U.S. Territories, January 1, 2016-April 25, 2017. Morb Mortal Wkly Rep 2017;66:615-21.

58 Lohse S, Pfuhl T, Berkó-Göttel B, et al. Pooling of samples for testing for SARS-CoV-2 in asymptomatic people. Lancet Infect Dis 2020;20:1231-2.

59 Clemente NS, Ramond A, Turchi Martelli CM, et al. Geographies of risk: emerging infectious diseases and travel health data. Travel Med Infect Dis 2020;36:101806.

60 Adams LE, Sanchez-Gonzalez L, Gonzalez RR. Risk factors for infection with Chikungunya and Zika viruses in a community-based cohort study in southern Puerto Rico. American Journal of Tropical Medicine and Hygiene 2019;101:18-19.

61 Walker CL, Ehinger N, Mason B, et al. Ultrasound prediction of Zika virus-associated congenital injury using the profile of fetal growth. PLoS One 2020;15:e0233023-e.

62 Adebanjo T, Godfred-Cato S, Viens L, et al. Update: interim guidance for the diagnosis, evaluation, and management of infants with possible congenital Zika virus Infection-United states, October 2017. Morb Mortal Wkly Rep 2017;66.

63 Henderson AD, Aubry M, Kama M, et al. Zika seroprevalence declines and neutralizing antibodies wane in adults following outbreaks in French Polynesia and Fiji. Elife 2020;9:e48460.

64 Netto EM, Moreira-Soto A, Pedroso C. High Zika virus seroprevalence in Salvador. Northeastern Brazil limits the potential for further outbreaks. mBio 2017:8:e01390-17.

65 Pomar L, Musso D, Malinger G, et al. Zika virus during pregnancy: from maternal exposure to congenital Zika virus syndrome. Prenat Diagn 2019;39:420-30.

66 Redivo EdeF, Bôtto Menezes C, da Costa Castilho M, et al. Zika virus infection in a cohort of pregnant women with Exanthematic disease in Manaus, Brazilian Amazon. Viruses 2020;12. doi:10.3390/ v12121362. [Epub ahead of print: 2811 2020]. 